\title{
Solar-Powered Ventilation of African Termite Mounds
}

\section{Citation}

Ocko, Samuel A., Hunter King, David Andreen, Paul Bardunias, J. Scott Turner, Rupert Soar, and L. Mahadevan. 2017. Solar-Powered Ventilation of African Termite Mounds. Journal of Experimental Biology 220: 3260-3269.

\section{Permanent link}

http://nrs.harvard.edu/urn-3:HUL.InstRepos:41302401

\section{Terms of Use}

This article was downloaded from Harvard University's DASH repository, and is made available under the terms and conditions applicable to Open Access Policy Articles, as set forth at http:// nrs.harvard.edu/urn-3:HUL.InstRepos:dash.current.terms-of-use\#OAP

\section{Share Your Story}

The Harvard community has made this article openly available.

Please share how this access benefits you. Submit a story.

Accessibility 


\title{
Solar-powered ventilation of African termite mounds
}

\author{
Samuel A. Ocko ${ }^{1, *, \S}$, Hunter King ${ }^{2, \ddagger, \S}$, David Andreen ${ }^{3}$, Paul Bardunias ${ }^{4}$, J. Scott Turner ${ }^{4}$, Rupert Soar ${ }^{5}$ and \\ L. Mahadevan ${ }^{6, \pi}$
}

\begin{abstract}
How termite mounds function to facilitate climate control is still only partially understood. Recent experimental evidence in the mounds of a single species, the south Asian termite Odontotermes obesus, suggests that the daily oscillations of radiant heating associated with diurnal insolation patterns drive convective flow within them. How general this mechanism is remains unknown. To probe this, we consider the mounds of the African termite Macrotermes michaelseni, which thrives in a very different environment. By directly measuring air velocities and temperatures within the mound, we see that the overall mechanisms and patterns involved are similar to that in the south Asian species. However, there are also some notable differences between the physiology of these mounds associated with the temporal variations in radiant heating patterns and $\mathrm{CO}_{2}$ dynamics. Because of the difference between direct radiant heating driven by the position of the sun in African conditions, and the more shaded south Asian environments, we see changes in the convective flows in the two types of mounds. Furthermore, we also see that the south Asian mounds show a significant overturning of stratified gases, once a day, while the African mounds have a relatively uniform concentration of $\mathrm{CO}_{2}$. Overall, our observations show that despite these differences, termite architectures can harness periodic solar heating to drive ventilation inside them in very different environments, functioning as an external lung, with clear implications for human engineering.
\end{abstract}

KEY WORDS: Animal architecture, Termite mounds, Ventilation

\section{INTRODUCTION}

Many animals build homes to buffer themselves from large fluctuations of the environment, while still being able to exchange information, energy and matter with their environs. A particularly dramatic example of this is seen in termite mounds. Although their individual size is typically on the centimeter scale, various termite species within the Macrotermitinae build structures that can be several meters in height. Most interestingly, these mounds are

${ }^{1}$ Department of Physics, Massachusetts Institute of Technology, Cambridge, MA 02139, USA. 2Paulson School of Engineering and Applied Sciences, Harvard University, Cambridge, MA 02138, USA. ${ }^{3}$ Department of Architecture and the Built Environment, Lund University, SE-221 00 Lund, Sweden. ${ }^{4}$ School of Environmental Sciences, State University of New York, Syracuse, NY 13210, USA. ${ }^{5}$ College of Art Design and Built Environment, Nottingham Trent University, Nottingham NG1 4FQ, UK. ${ }^{6}$ Department of Physics, Department of Organismic and Evolutionary Biology, Wyss Institute for Bioinspired Engineering, Kavli Institute for Bionano Science and Technology, Harvard University, Cambridge, MA 02138, USA.

*Present address: Department of Applied Physics, Stanford University, Stanford, CA 94305, USA. ₹Present address: Department of Polymer Science, Department of Biology, University of Akron, Akron, OH 44325, USA.

$\S$ These authors contributed equally to this work

"Author for correspondence (Imahadev@g.harvard.edu)

(D) L.M., 0000-0002-5114-0519

Received 8 April 2017; Accepted 25 June 2017 hollow porous structures that extend well above the densely inhabited subterranean nest and the fungus the termites cultivate.

The termite mound has long been considered to facilitate climate control, which includes regulation of temperature, humidity and respiratory gas concentrations. Various studies, focusing on individual species, have emphasized one or another of these different objectives and proposed different mechanisms for exactly how the insects, fungi and encapsulating structures are able to create an internal microclimate that buffers the inside from changes in ambient environmental conditions, while eliminating chemical byproducts of their own metabolic activity.

An early hypothesis (regarding Macrotermes natalensis mounds) suggested that internal metabolic heating drives convective flow, primarily to regulate temperature but also to promote exchange of respiratory gases (Luscher, 1961). Later work (on Macrotermes bellicosus) suggested that external heating may play an additional role (Korb, 2003; Korb and Linsenmair, 2000). Alternatively, other studies have demonstrated that temperature control need not be assisted by ventilation (Odontotermes transvaalensis; Turner, 1994), and that exchange of respiratory gases is the primary role of the mound, pointing to external forcing from turbulent wind as the driving mechanism (Macrotermes michaelseni; Turner, 2001). In each case, flow velocities within the mound were inferred from measurements of indirect quantities: temperature, clearance rates of injected tracer gas and natural concentrations of $\mathrm{CO}_{2}$. [A custom anemometer was designed and applied for direct measurement by Loos (1964), but its own thermal coupling to the interior and slow thermal equilibration rendered its interpretation of average directional flow ambiguous (see 'Notes added by the author after the discussion' in Loos, 1964).]

Recently, we built a custom sensor to directly characterize airflow inside the (Odontotermes obesus) mound (King et al., 2015). The main conclusion drawn from our measurements is that respiratory gas exchange can be achieved by a much simpler mechanism than had been previously thought: daily temperature oscillations were shown to drive convective flow, which reverses twice a day and thus serves to ventilate the mound. Furthermore, the study showed that neither wind, of which there is little to be found locally, nor metabolism played a role in ventilation, contrary to prior hypotheses. Because daily oscillations in radiative heating are a fact of life on our planet, this mechanism is likely to be generic across different species of mound-building termites, as it depends only on the minimal characteristics of mound structure, which provides a thermal envelope with an inhomogeneous thermal inertia. However, given that there are variations in the climes that different species of termite inhabit, a natural question is how the mechanism of ventilation is affected by differences in local environmental conditions, mound structure and physiology.

In contrast to the relatively humid, nearly uniformly warm environment encountered by $O$. obesus mounds in south Asia, Macrotermes michaelseni mounds experience relatively more direct sun in the semi-arid environment associated with the southern 
African savanna, with large highs and lows $\left(\Delta T \approx 15-20^{\circ} \mathrm{C}\right.$ when our measurements were made). Furthermore, M. michaelseni mounds more often experience strong winds of up to $\sim 5 \mathrm{~m} \mathrm{~s}^{-1}$ average (see Appendix 4, Fig. A4) in contrast to the nearly wind-less environments of the tree-laden south Asian temperate regions that are the home of $O$. obesus mounds. In addition, from a structural perspective, the $M$. michaelseni mounds lack the buttress-like features prominent in $O$. obesus mounds, which appear to aid the harnessing of daily temperature variation for flow (King et al., 2015). Given these differences, similarities in the fluid dynamics and ventilative function of these disparate mound types would be suggestive of a generic mechanism, likely to be found in other biological structures.

Therefore, we aimed to characterize the internal bulk airflow and determine its driving force, considering two plausible candidates: external wind (average and fluctuations) and thermal gradients within the mound. We also compare daily schedules of internal $\mathrm{CO}_{2}$ concentration to connect measured physical flows with their role in respiratory function.

\section{MATERIALS AND METHODS}

To characterize the internal gas transport mechanism and identify its dominant driver, we made direct measurements of average and transient airflow inside the mound, external wind near the mound, $\mathrm{CO}_{2}$ concentrations and temperature in various parts of the mound, each performed throughout the $24 \mathrm{~h}$ cycle to observe the full variation and diurnal patterns. All measurements were made from 15 April to 20 May in 2014 and 2015 on the properties of the Cheetah Conservation Fund in Otjiwarongo, Namibia (S20 $30.39^{\prime}$, E16 $\left.58.35^{\prime}\right)$.

\section{Termite mound structure}

Externally, the mounds can be seen to protrude 1-3 $\mathrm{m}$ above ground, usually an approximately conical base supporting a narrower spire, which tends to tilt slightly northward (Turner, 2000), as seen in Fig. 1A. The exterior walls are made of a porous, brittle material, with sparsely distributed but visible holes of $\sim 5 \mathrm{~mm}$ on the surface, which may extend to the interior, particularly in areas of active construction. [Percolation of external holes to the interior is inferred from two observations: (1) liquid metal, while casting, has leaked to the surface; and (2) smoke injected inside has emerged from the surface near active building sites. This seems more pronounced during the rainy season, when building is more frequent.] Namibian mounds are built using soil derived from aeolian sands with minimal clay content (Dangerfield et al., 1998) compared with that in India.

The internal structure of the mound is characterized by a network of broad conduits $(\sim 2-10 \mathrm{~cm}$ diameter, many times the length of an individual termite) running from the underground nest and fungus galleries to the top, leading to a structure that connects the center with the periphery very well (Turner, 2000). The conduits can be visualized by endocasting: pouring plaster into the interior, letting it set and washing away the mound material to expose the interior volume (Ruelle, 1964; Turner and Soar, 2008), as seen in Fig. 1B.

\section{Internal flow}

To measure the slow airflow inside the mound, a custom-made device was inserted into vertically oriented surface conduits, approximately $1 \mathrm{~m}$ above ground level. The device's operating principle is a variant of standard hot-bead anemometry (King et al., 2015). Diffusion of heat from a $0.3 \mathrm{~mm}$ diameter thermistor bead is measured by two identical beads arranged in a line on either side.
The center bead can be pulsed for measurement of average flow or continuously heated for measurement of transient flow. A similar, passive probe function without a central heating bead was also used to measure temperature fluctuations. This allows for independent measurement of average flow, transient flow and thermal variation in a given conduit at a given time. In the event of termites biting or depositing mud near the beads, the cheap thermistor beads were simply replaced and the device was recalibrated within hours.

In the pulsed mode of operation, $\sim 47 \mathrm{~V}$ is briefly (140-700 ms) applied to the center bead, creating a small bolus of warm air around it. The direction and magnitude of surrounding flow was quantified by a metric comparing the relative magnitude in temperature peaks measured in each neighboring bead, as the diffusion of the bolus was biased in one or the other direction. To improve accuracy, the bead was pulsed every $10 \mathrm{~s}$ and responses were averaged over many pulses. The metric was translated to actual flow velocity by calibrating the response in a controlled setup to prescribed flow velocity, in the same manner as in King et al. (2015).

To measure transient variations in flow about its average value, the center bead is continuously heated (continuous heating causes the device to create its own convective currents, making the average flow values ambiguous; the average flow values are measured using the pulsed mode). When the flow becomes more upwards (downwards), the upper bead simultaneously becomes warmer (cooler), and the lower bead becomes cooler (warmer) (there is a warm-up phase of $\sim 15 \mathrm{~s}$; this is subtracted). This shows up as anticorrelated fluctuations in the readings of the two beads on top of thermal drift; these anti-correlated fluctuations can be quantified and converted to a rough velocity through calibration in the same calibration tube used for the average flow calibration, but by varying prescribed flow.

A total of 121 steady and transient measurements from $~ 30$ mounds were made at various times of the day. Each measurement was made in large vertical conduits accessed through drilling with a hole saw at a height of $\sim 1 \mathrm{~m}$ from ground level. Measurements were made for $\sim 1.5$ min each, to minimize interference and damage by termites. Proper positioning of sensor along vertical conduits of sufficient diameter was ensured by inspection of local geometry using a finger. Along with velocity measurements, we also recorded the time of day and the orientation of the conduit relative to the mound center.

\section{Wind}

Instantaneous wind speed and direction next to the mound was measured during each of the internal flow measurements with a cup-and-vane anemometer (Wind101 compact weather station, threshold speed $0.43 \mathrm{~m} \mathrm{~s}^{-1}$, distance constant $\sim 2.5 \mathrm{~m}$, Barani Design, Dubova, Slovakia) fixed $\sim 2 \mathrm{~m}$ above ground within $\sim 3 \mathrm{~m}$ of the mound being measured.

\section{Mound temperatures}

Temperature profiles were obtained by implanting iButtons (DS1922L, Maxim Integrated, San Jose, CA, USA) into the mound using a hole saw and closing the openings with wet mud. Eight iButtons were placed at a height of $\sim 1 \mathrm{~m}, \sim 5-10 \mathrm{~cm}$ below the surface at the north, northeast, east, etc. sides of the mound, in the neighborhood of locations where velocity measurements were also made. iButtons were also placed in the nest $(\sim 0.5 \mathrm{~m}$ below ground), center (along the central axis at a height of $\sim 1 \mathrm{~m}$ ) and top (along the central axis $\sim 15 \mathrm{~cm}$ from the top) to allow for rough calculation of thermal gradients through the daily cycle. 


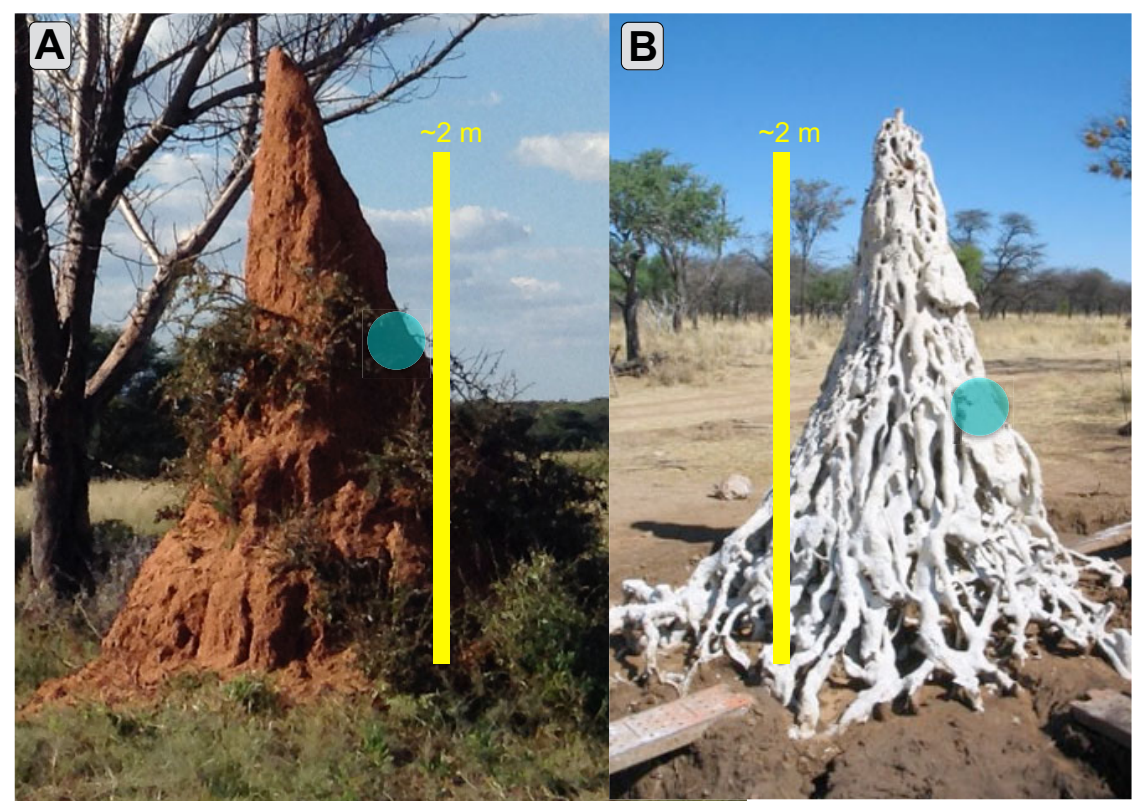

Fig. 1. Mounds of Macrotermes michaelseni. (A) Side view of a mound. (B) Filling the mound with gypsum, letting it set, and washing away the original material reveals the interior volume (white regions) as a continuous network of conduits, shown. Typical conduits we recorded from are highlighted in blue.

To obtain a fuller picture of the behavior of mound temperatures through the year, we compared our measurements taken in May 2014 and 2015 against a dataset of annual variation of mound temperature measured in an M. michaelseni mound taken from February 2004 through January 2005 by J.S.T. Temperatures were measured using iButtons implanted in the mound and set to record a measurement every $4 \mathrm{~h}$. We compared superficial temperatures, i.e. the temperature roughly $10 \mathrm{~cm}$ below the mound's north surface (NS) versus its south surface (SS).

\section{$\mathrm{CO}_{2}$ levels}

Tubes of $6 \mathrm{~mm}$ inner diameter, length $\lesssim 1 \mathrm{~m}$ were inserted into three locations along the central axis of a $\sim 3$ m mound: in the nest $\sim 0.5 \mathrm{~m}$ below ground (that the nest was accessed, and not some other part of the mound, was inferred from the fact that the drill bit broke into an apparently deep, roughly central cavity, and was subsequently withdrawn with fungus stuck to it), and in the center of the chimney $\sim 1 \mathrm{~m}$ and $\sim 2 \mathrm{~m}$ above ground. Between installation and measurement, the tubes were left overnight, when termites conveniently sealed the gap between the drilled holes and the tubes, forming a seal resistant to tugging. Surprisingly (as it posed a significant problem in $O$. obesus mounds), the ends of the tubes in the interior were left unsealed, as could clearly be distinguished by the insignificant resistance to drawing air out by mouth. For most of an uninterrupted $24 \mathrm{~h}$ cycle, volumes of air $(\sim 500 \mathrm{ml})$ were drawn with a syringe every $15 \mathrm{~min}$ from each tube, directed through a small chamber containing an optical $\mathrm{CO}_{2}$ sensor (Cozir wide range IR LED $\mathrm{CO}_{2}$ sensor, CO2Meter.com, Ormond Beach, FL, USA). For each measurement, the volume was drawn in small increments to allow for diffusion across the internal permeable membrane of the sensor, indicated by a plateau in its response. Between measurements, the sensor was flushed with clean (external) air to ensure independence of each measurement.

\section{RESULTS}

\section{Bulk flow and thermal gradients}

Fig. 2A shows the aggregate daily schedule of average internal flow in surface conduits of roughly 30 mounds in the area. Despite a large, though expected, variation in flow speeds, a robust trend can be seen: air flows strongly down the conduits at night, and, on average, upward during the day. This observation is largely consistent with the pattern in O. obesus mounds in India (King et al., 2015), where the flow simply tracked the axisymmetric temperature difference between chimney and conduits. One notable deviation in the flow profiles relative to that in O. obesus mounds is that air in some surface conduits of $M$. michaelseni mounds flows downward during the day. Related to this, the pattern of internal temperatures (Fig. 2B), indicates an azimuthal dependence, as the eastern conduit warms first in the morning, followed by the northern and then western conduits, and the southern side remains coolest throughout. This trend follows the path of the sun, which is directly incident on the surface of most mounds. Convection driven by these orientationally dependent gradients could therefore involve downward flow in shaded surface conduits at roughly predictable times of day. Using:

$$
\Delta T(t, \phi)=T_{\text {periphery }}(t, \phi)-T_{\text {center }}(t)
$$

where $t$ is the time of day and $\phi$ is the orientation, we estimate the temperature gradient between the center and any given conduit of a given mound. When internal flow velocity is plotted against $\Delta T(t, \phi)$, the data collapse to a more distinct trend, with fewer daytime points going against the trend (Fig. 2, bottom). This produces a correlation of 0.76 with the flow velocities measured, and drops to 0.63 when orientational information is not taken into account, and the gradient is estimated from the average periphery temperature $\left[\Delta T(t)=\bar{T}_{\text {periphery }}(t)-T_{\text {center }}(t)\right]$, indicating the relative importance of time and orientation. We suspect that many of the measurements going against the average trend are due to the complex tunnel geometry; this is a generic feature of flow through disordered, porous media (Datta et al., 2013; Lebon et al., 1996).

\section{$\mathrm{CO}_{2}$ and diffusive transfer}

Additionally, over the period of our experiments that corresponds to late summer/early fall in the southern hemisphere, there were no large gradients of $\mathrm{CO}_{2}$ within the mound, and levels stayed close to $5 \%$ throughout the whole period, as shown in Fig. 3. In several other 

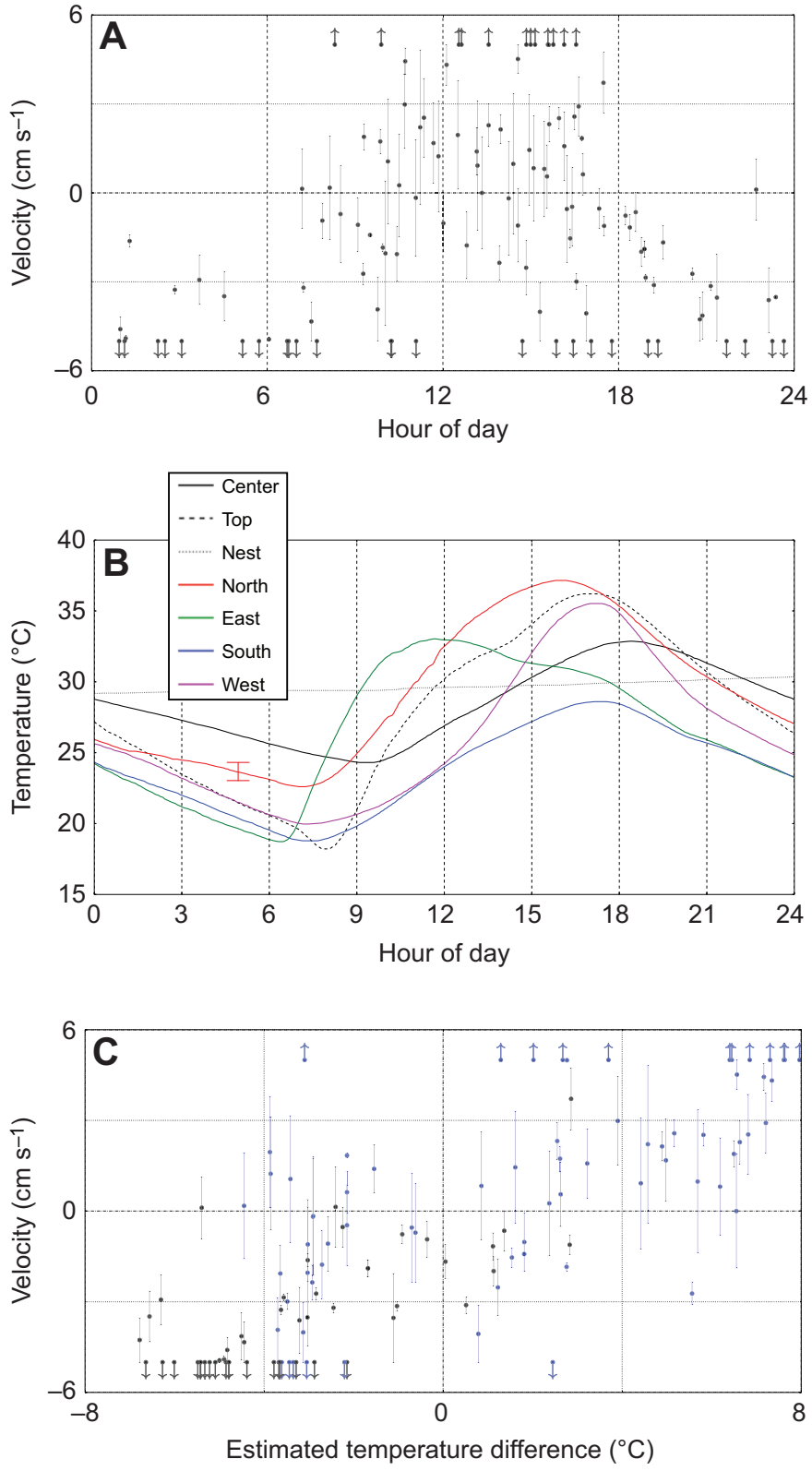

$\Delta T(t, \phi)$

Fig. 2. Internal mean flow velocity and temperature gradients. (A) Scatter plot of air velocity in surface conduits as a function of hour of day; a positive (negative) velocity means upwards (downwards) flow. Each data point consists of two 1.5 min measurements with different probe positioning (see Appendix 2); error bars represent the difference between these two measurements. (B) Thermal schedule of a mound. Note that the east side reaches its warmest point during the morning as the sun rises and the west side reaches its warmest point during the afternoon as the sun sets. As these mounds are located in the southern hemisphere, the north side receives much more direct sunlight than the south side, and is hotter at all times of the day. (C) Measured air velocity versus temperature gradient $\Delta T(t, \phi)$, where $\phi$ is the orientation of a conduit relative to the center of a mound (north, northeast, east, etc.). Daytime measurements (11:00-17:00 h) are colored in blue. Note that many daytime measurements with downwards flow fall in the lower-left quadrant, indicating the importance of both time and orientation on flow velocity. The large red/black error bars in $B$ and $C$ indicate the $0.5^{\circ} \mathrm{C}$ accuracy from all iButton measurements. Data points with arrows indicate that the measurement was beyond the calibrated scale of the flow sensor in the indicated direction.

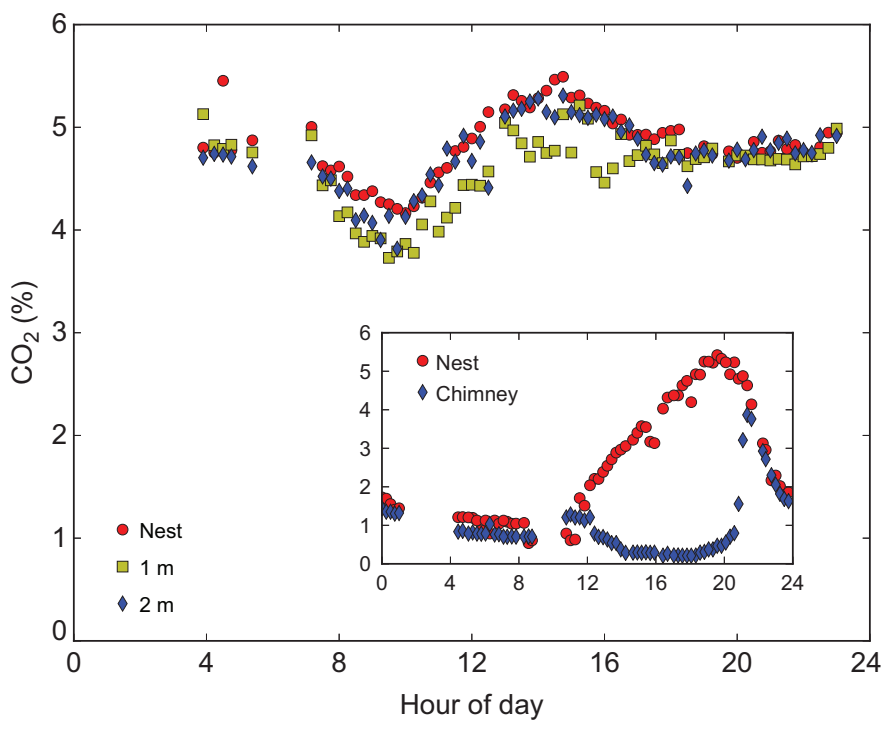

Fig. 3. Daily $\mathrm{CO}_{2}$ schedule of an M. michaelseni mound. $\mathrm{CO}_{2}$ concentrations were measured both in the below-ground nest and directly above the nest, approximately 1 and $2 \mathrm{~m}$ from the ground. The relatively steady and uniform concentrations indicate transport is limited by transport across the surface rather than internal mixing. Inset: corresponding data from the nest and mid-chimney of an Odontotermes obesus mound in India (King et al., 2015). Sensor error in both cases is at most $\pm 0.18 \% \mathrm{CO}_{2}$.

mounds, the $\mathrm{CO}_{2}$ levels were also between 4 and $6 \%$ just inside the exterior wall, a relatively small variation. This must be contrasted with our observations of the $O$. obesus mounds in south Asia, which show a clear diurnal oscillation of $\mathrm{CO}_{2}$ concentrations within a period of $24 \mathrm{~h}$.

Because gas exchange with the environment requires both sufficient bulk flow between the nest and the mound and diffusive exchange across the mound wall, one can expect a rise in $\mathrm{CO}_{2}$ owing to attenuation of either process. The cycle of stagnation and refreshing of nest air in Indian mounds (see inset of Fig. 3) is consistent with the cycle of weak and strong bulk flow. The homogeneity in $\mathrm{CO}_{2}$ of the African mounds, by contrast, suggests that while bulk flow sufficiently mixes internal air, respiratory exchange is largely limited by the rate of diffusive transfer through the walls during the months of April and May. However, at other times of the year, lower levels and larger gradients of $\mathrm{CO}_{2}$ have been observed (Turner, 2001), suggesting the possibility that the mound walls are remodeled over the course of one year.

We note that while $\mathrm{CO}_{2}$ is well mixed within the mound, an internal temperature gradient is still maintained; these transport processes diverge because the ability of the mound material to store and conduct heat.

\section{Transient component}

In principle, transient, sloshy flows alone can intermittently mix gas in the mound sufficiently to facilitate exchange between the nest and the environment. Unlike measurements in O. obesus mounds in India, where fluctuations in average flow could not be distinguished from noise, we find significant fluctuating flows in the surface conduits in M. michaelseni mounds. There are two plausible sources of velocity transience: (1) transient pressure differentials incident on the surface from external wind, and (2) plume-like instabilities in the thermally driven average flows, because of rapid heating and cooling of traveling air. To isolate the possible role of wind (1), we compared the internal transience measurements against recordings 


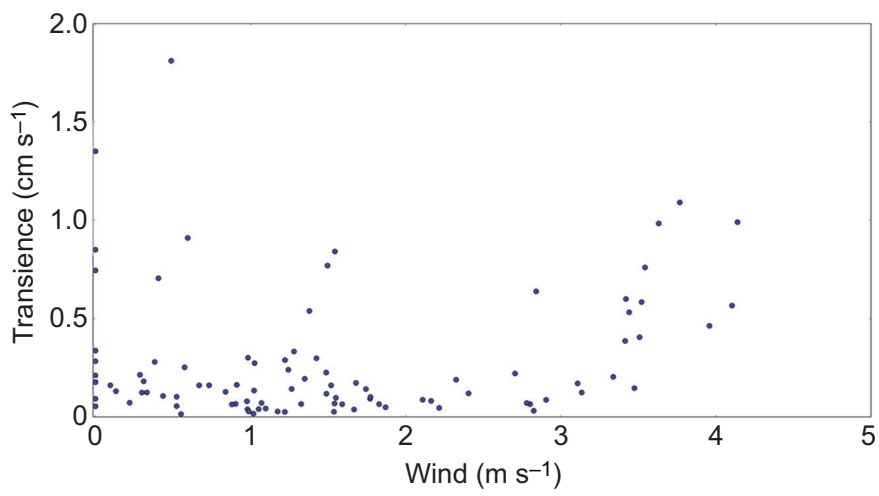

Fig. 4. Magnitude of internal transient flows as a function of average external wind speed. Large and small values of transience are distributed over all ranges of wind speed, though values appear somewhat correlated above $3 \mathrm{~m} \mathrm{~s}^{-1}$ (see Appendix 3).

of wind speed from outside the mound, as summarized in Fig. 4. There, we see uncorrelated values of transient flow from zero to $\sim 1 \mathrm{~cm} \mathrm{~s}^{-1}$ for all values of external wind, and evidence of windtransient flow correlation only for external wind above $\sim 3 \mathrm{~m} \mathrm{~s}^{-1}$.

These data clearly do not support a model in which wind is the sole driver of internal transient flows. Judged over the whole 24-h cycle, external wind is poorly correlated with measured internal transience, as large values are often found at night, when there is typically little to no wind. However, we do find a significant correlation (0.51) when limited to daytime (11:00-17:00 h) measurements, where wind values tend to be higher (see Appendix 3). This indicates that while wind is not the main driver of transient flows in general, it is likely a significant contributor on windy days and windier moments during the day (see Appendix 3).

Using a passive probe, in which the thermistors simply track temperature, we have observed thermal fluctuations on the order of $\sim 0.2^{\circ} \mathrm{C}$ (see Appendix 4). While additional tests (e.g. fine spatial variation in temperatures) would be necessary to quantitatively characterize the thermal heterogeneity, the fluctuations appear to be consistent with those of high Rayleigh number (plume-like) flows (2).

It is important to note that the magnitude of transients measured are smaller in magnitude than the average flow $90 \%$ of the time, and that unidirectional flow is far more effective in bulk transport of gas than that of 'sloshy' mixing. In other words, at most times, the transient flow component represents an alternating slowing and speeding of flow in one direction, rather than an oscillatory flow about mostly stationary air.

\section{DISCUSSION}

Termite mounds are an inspiring example of an animal-engineered, passively ventilated structure, and they raise a fundamentally important question that has not been answered owing to the previous inaccessibility of direct measurements: how does air move in the mound and what pushes it? Previous studies pointing to less direct evidence have answered with two hypotheses: either 'sloshy, pushed by gusts of wind' or 'smoothly convective, pushed by metabolic heating'.

Our study shows that air in the mounds of the African termite M. michaelseni moves largely as a convective cell following a diurnally oscillating thermal schedule, where the periphery tracks temperature variations that are more damped in the center, with an additional azimuthal thermal modulation associated with the periphery as it is directly heated by the sun, as illustrated in Fig. 5.

We find that over the course of our measurements, wind plays a subordinate role (relative to the dominant thermal mechanism) in inducing either average or transient flows within the mound. However, we note that it is probable that wind will enhance the transfer of gas near the surface (which would otherwise happen more slowly via diffusion alone), especially when there are open tunnels (e.g. egress complex Turner and Soar, 2008) percolating to the interior. Previous observations of tracer gas clearance (Turner, 2001) in M. michaelseni mounds and transient 'gusts' (Loos, 1964) in $M$. natalensis mounds, both qualitatively correlated to external wind events, could, in the context of the present study, be reconciled with our results by the possibility that such tunnels are opened seasonally to supplement thermal-driven ventilation. Our measurements were made in the dry season, when relatively less permeability and building activity has been observed (Turner et al., 2006).

Overall, our results demonstrate that the mechanism for respiration in M. michaelseni mounds is similar to that of O. obesus (King et al., 2015), with two notable exceptions: (1) direct sunlight creates angular thermal gradients in addition to the radial thermal gradients caused by oscillations in ambient temperatures; and (2) $\mathrm{CO}_{2}$ is, by comparison, well mixed throughout the $24 \mathrm{~h}$ cycle, and remains close to $5 \%$,

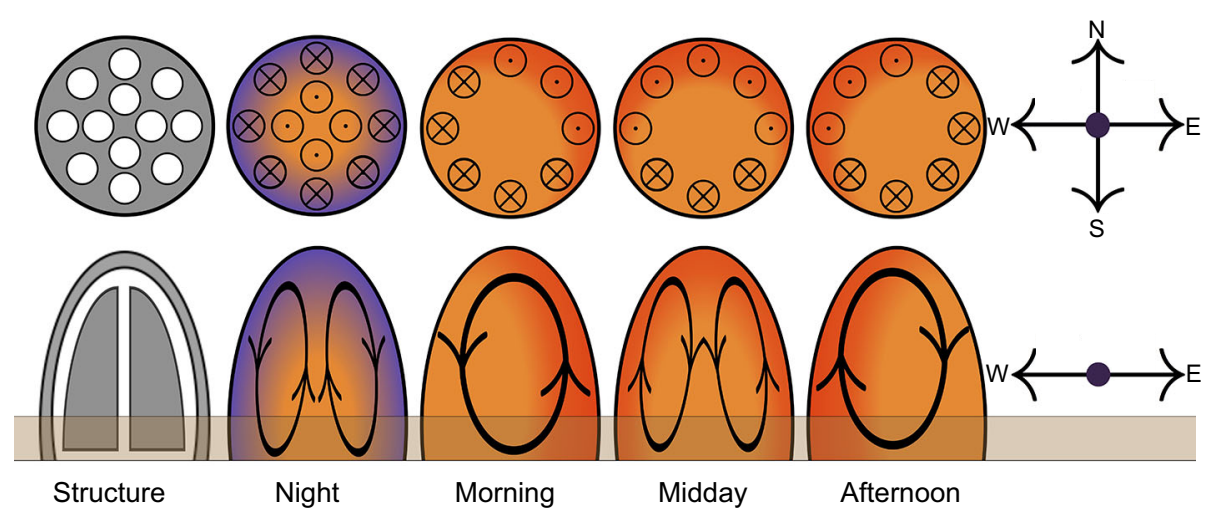

Fig. 5. Schematic of the thermal/airflow schedule of a mound viewed from the top and the side. During the daytime (nighttime), the periphery is hotter (colder), while the center stays cool (warm), creating a convection cell with upwards (downwards) flow in the periphery and downwards (upwards) flow in the center. This basic mechanism is complicated somewhat by direct solar heating. During the morning, the sun directly heats the east side of the mound, which will be hotter than the west side; during the evening, the west side is hotter than the east. In addition, the north side of the mound consistently receives more sunlight than the south side (mounds are in the southern hemisphere). Air velocity measurements could not be taken deep inside the mound, so the exact boundary between upwards and downwards flow is not known. 
suggesting that respiration is limited more by slow transfer of gas across the surface than by slow transport via bulk flow from the nest. The mounds of $M$. michaelseni, exposed to much larger thermal fluctuations than those of $O$. obesus, do not have the same 'radiatorlike' architecture which might enhance thermal gradients. It remains to be seen whether this is an adaptation for ventilation in different environments.

Taken together with King et al. (2015), we find that the dominant mode of ventilation in the mounds of two termite species that live in rather disparate environments is due to diurnal cycles of (direct and indirect) solar heating that, combined with thermal lag, lead to largescale convective flows between the periphery and the interior. It would not be surprising if similar ventilation mechanisms are at work not just in other termite species, but more broadly, in other animal architectures, given the minimal ingredients required: a sufficient spatial variation in thermal inertia that, when coupled to temporal variations in the environment, can be used to derive mechanical work.

\section{APPENDIX 1}

\section{Prediction of mean flow speed}

As a model for a convective circuit within a termite mound, we choose a pipe radius $r$, in the shape of a closed vertical loop of height $h$, where the temperature difference between the left and right side of the loop is $\Delta T$. The total driving pressure is $\rho \alpha \Delta T g h$, where $\rho$ is air density and $\alpha$ is the coefficient of thermal expansion, and
Poiseuille's law gives:

$$
Q=\underbrace{\rho \alpha \Delta \operatorname{Tgh}}_{\text {Driving pressure }} \cdot \underbrace{\frac{\pi r^{4}}{8 \mu h \cdot 2}}_{\begin{array}{c}
\text { Poiseuille } \\
\text { resistance } \\
\text { of conduits }
\end{array}},
$$

where $Q$ is the volumetric flow rate, $\mu$ is the dynamic viscosity and the factor of 2 comes from the resistance on both sides of the loop. Calculating internal flow speed:

$$
V_{\text {internal }}=\frac{Q}{\pi r^{2}}=\frac{\rho \alpha \Delta T g r^{2}}{16 \mu}
$$

and plugging in values of $\Delta T=6^{\circ} \mathrm{C}, r=3 \mathrm{~cm}, \mu / \rho=0.16 \mathrm{~cm}^{2} \mathrm{~s}^{-1}$ and $\alpha=1 / 300^{\circ} \mathrm{C}$, we obtain a result of $\sim 70 \mathrm{~cm} \mathrm{~s}^{-1}$. This speed is $\sim 10$ times higher than those observed, likely because of oversimplification of internal geometry; disorder and variation in conduit size favors high resistance bottlenecks, which reduce the mean flow speed. The calculation demonstrates that observed thermal gradients and crude dimensions are sufficient to produce flow of the order measured.

Crude measurements of the microscopic permeability of mound material, $\mathbf{k}$ (in the manner of King et al., 2015), give upper-bound estimates of $0.03 \mathrm{~cm} \mathrm{~s}^{-1} \mathrm{~Pa}^{-1}$ (although it was difficult to make a good seal to measure permeability, these errors would only increase the measurement). From this we can estimate the flow through the
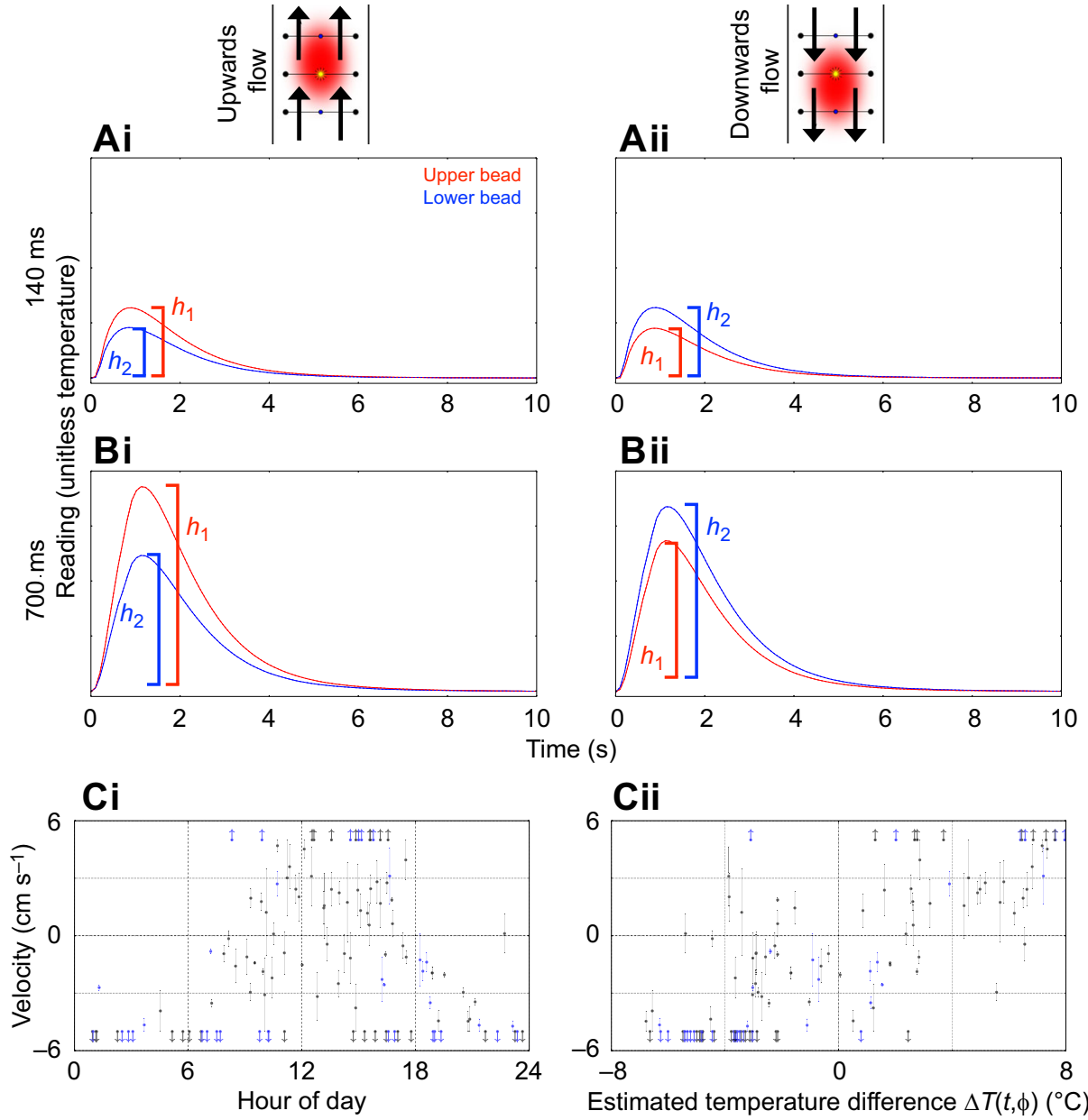

Fig. A1. Schematic of the air flow sensor. When the central bead is pulsed, the warm air flows to either the upper or lower bead depending on the airflow. The relative magnitude of response on each bead can be measured to predict the direction of airflow. (A) Example response curves using a $140 \mathrm{~ms}$ pulse length with $1.7 \mathrm{~cm} \mathrm{~s}^{-1}$ upwards (downwards) flow, which increases the response of the upper (lower) bead while decreasing the response of the lower (upper) bead. (B) Response curves using a $700 \mathrm{~ms}$ pulse length. Two notable differences are (1) increased height due to increased pulse magnitude and (2) slight upwards bias due to increased buoyancy of the bolus. Both of these effects can be, and are, calibrated out. (C) All average flow data. Measurements taken with a $700 \mathrm{~ms}$ pulse length are highlighted in blue, confirmation that these effects have been controlled for. 
mound surface owing to buoyancy-driven convection:

$$
V_{\text {external }}=\underbrace{\rho \alpha \Delta \operatorname{TgH}}_{\text {Driving pressure }} \cdot \underbrace{\mathbf{k}}_{\begin{array}{c}
\text { Mound wall } \\
\text { conductivity }
\end{array}},
$$

where $H$ is the height of the mound. Plugging in $H=2 \mathrm{~m}$, we obtain a result of $V_{\text {external }} \approx 0.015 \mathrm{~cm} \mathrm{~s}^{-1} \ll V_{\text {internal }}$, meaning that the dominant flows travel cyclically through the conduits, and mound walls are effectively closed to thermally driven convection currents.

\section{APPENDIX 2}

\section{Average flow calibration and pulse length}

Our probe consists of three $0.3 \mathrm{~mm}$ diameter glass coated thermistor beads (Victory Engineering Corporation, Springfield, NJ, USA; $R_{0}=20 \mathrm{k} \Omega$ ) held exposed by fine leads in a line with $2.5 \mathrm{~mm}$ spacing. To measure average flows, the center bead is used as a pulsed heat source. As the heat diffuses outward, its bias depends on the direction and magnitude of flow through the sensor, as depicted in Fig. A1. The operating principle is similar to that of some sensitive pulsed wire anemometers (Olson et al., 1984). Flow is quantified by comparing the signals (effectively temperatures) from either neighboring bead.
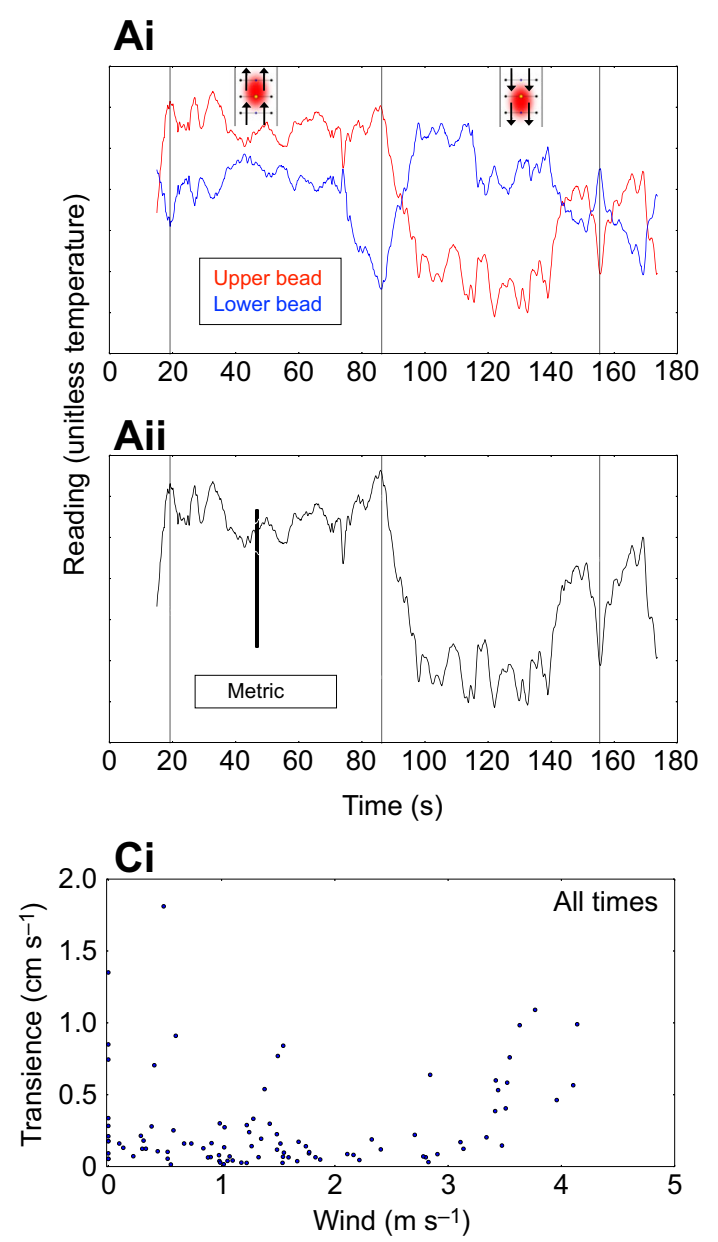

In order to accurately measure airflows, we needed to have a pulse size large enough to overcome thermal transients. However, there is an inherent trade-off. A pulse that is too small will not provide a large enough signal to overcome the thermal noise observed; in contrast, a pulse that is too large will create more thermal buoyancy that might be sensitive to tunnel geometry. We balance these tradeoffs with a pulse length of $140 \mathrm{~ms}$, which creates a buoyancy bias of $\sim 1 \mathrm{~cm} \mathrm{~s}^{-1}$. When thermal transience is too large for the signal to overcome, the pulse length is increased to $700 \mathrm{~ms}$ for that measurement, giving an increase in signal at the expanse of additional thermal buoyancy $\sim 2 \mathrm{~cm} \mathrm{~s}^{-1}$. We can confirm that the observed trend is the same regardless of pulse length in Fig. A1.

To control for systematic errors related to asymmetric bead response, we calibrate the probe in both symmetrically aligned orientations (differing by $180 \mathrm{deg}$ ). To estimate random error coming from geometry, each data point consists of two $1.5 \mathrm{~min}$ measurements, one for each orientation. The difference between these measurements, coming mostly from variations in alignment with respect to the internal conduit, is reported in the error bars; the standard deviation given by the statistics of individual pulse responses is smaller $\left(\sim 6 \mathrm{~mm} \mathrm{~s}^{-1}\right)$ and does not reflect the uncertainty.
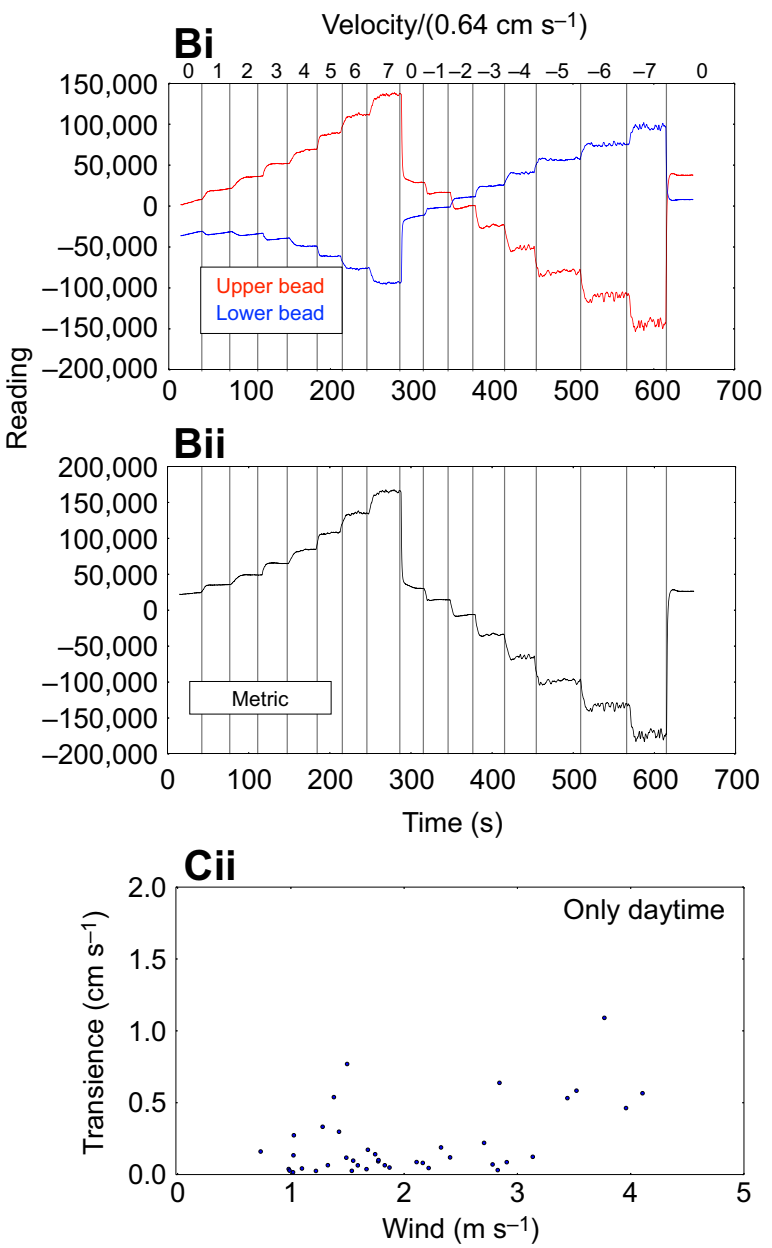

Fig. A2. Internal transient flow and external wind. (Ai) Raw transient data from a continuously heated bead. The anti-correlated 'jumps' in the readings of the upper and lower beads come from fluctuations between upwards and downwards flows. (Aii) Projection of bead readings onto the anti-correlated principal

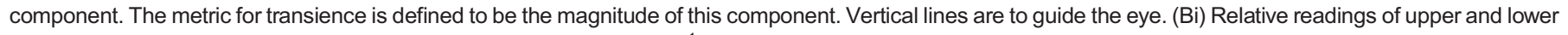

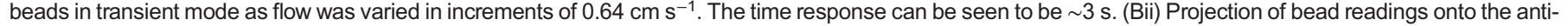
correlated principal component. (Ci) The magnitude of transience is largely uncorrelated with wind speed when measurements from all times of day are used. (Cii) The magnitude of transience is correlated with wind speed when measurements are limited to daytime (11:00-17:00 h), when the wind tends to be the highest. 


\section{APPENDIX 3}

\section{Velocity transients}

Transient mode function

When the sensor is run in transient mode, continuous voltage $47 \mathrm{~V}$ is applied across the middle bead, such that transients in the flows can be measured from the instantaneous, relative responses in the neighboring beads. The trade-off is that information about the baseline flow is lost, because induced currents, which depend on several parameters, including unknown details of tunnel geometry, can dominate the signal. As a crude measure of transient flow magnitude ('transience'), we subtract the thermal drift, perform a principal component analysis of the readings, and define transience to be the magnitude of the anti-correlated principal component (Fig. A2Ai).

This reading can be converted to a rough velocity through calibration in the same calibration tube used for the average flow calibration, but by varying prescribed flow. At low speeds $\left(<2 \mathrm{~cm} \mathrm{~s}^{-1}\right)$, the dependence of the metric on velocity is weaker $\left(\sim \frac{30,000}{\mathrm{~cm} \mathrm{~s}^{-1}}\right)$; we calibrate transience to velocity assuming this slope.

\section{Daytime wind-transience comparison}

When all wind-transience pairs are looked at, there is a small correlation between wind and transience $(0.17)$ that is not significant $(P=0.09$, permutation test) (Fig. A2Ci). When only daytime (11:00 17:00 h) measurements are used, the correlation becomes larger (0.51) and significant $\left(P=3 \times 10^{-3}\right.$, permutation test) (Fig. A2Cii). This suggests that while wind is not the dominant source of transients, it is likely a significant contributor on windy days.

\section{APPENDIX 4}

\section{Thermal transients}

Using a modified probe without a central heating bead and having even more exposed outer beads, we observe highly correlated fluctuations in bead temperatures (Fig. A3), indicating that the beads are measuring thermal fluctuations of some shared body of air. These thermal fluctuations are on the order of $\sim 0.2^{\circ} \mathrm{C}$, indicating that one source of velocity fluctuations is likely to be heat rising in plumes. While thermal transience is highly correlated with velocity transience, it is difficult to rigorously decouple the two quantities, especially in circumstances when, for instance, owing to large average flow, both thermal and flow transient metrics depend mostly on the overwhelming signal from one bead in either functioning mode. Therefore, the correlation is technically ambiguous. However, it qualitatively appears that thermal

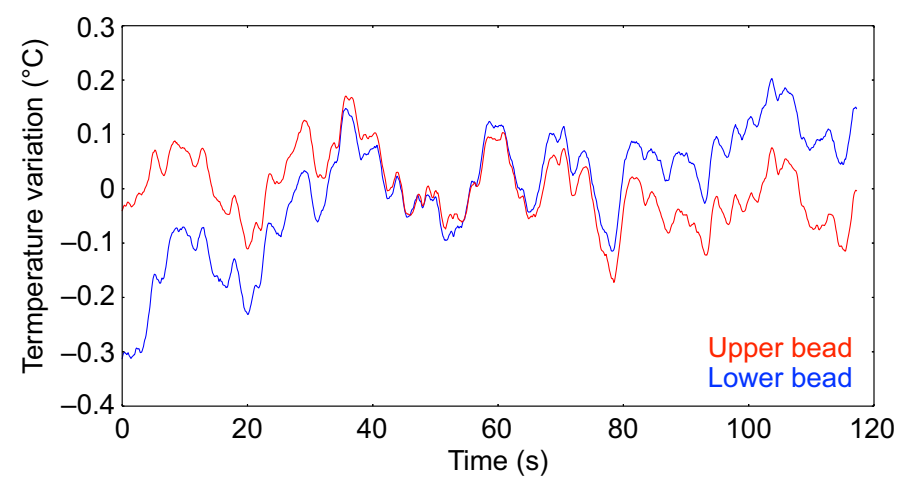

Fig. A3. Reading from thermal transience sensors. Note the correlated fluctuations in temperature between beads.
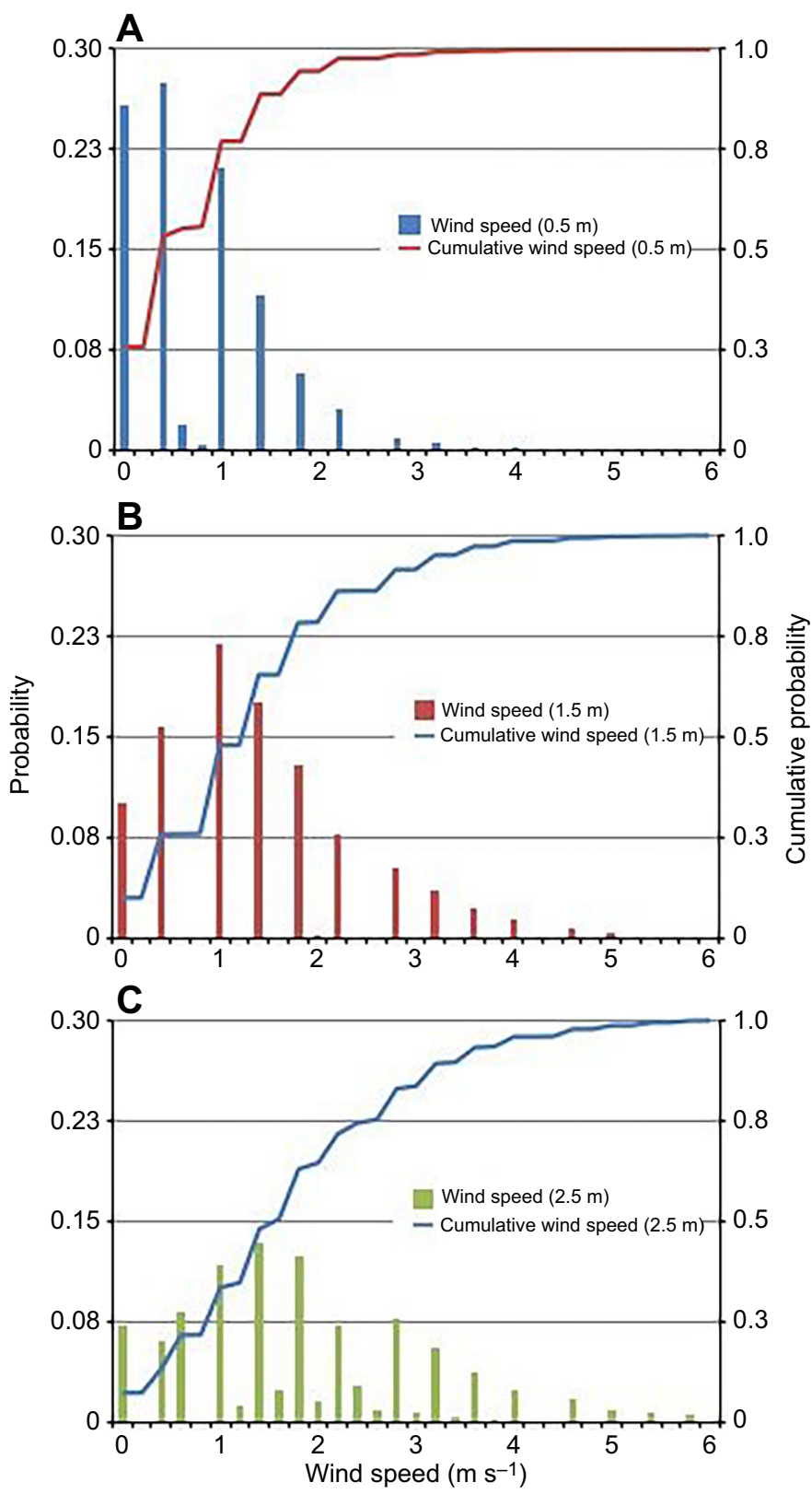

Fig. A4. Wind speed probability distribution, measured at $0.5,1.5$ and $2.5 \mathrm{~m}$ above ground.

heterogeneity is largely responsible for transient flows, because of the fact that: (1) thermal fluctuations are observed, and thermal fluctuations will always cause some velocity fluctuations, and (2) there does not seem to be another candidate source of energy to drive many of the observed velocity fluctuations that occur in absence of wind.

\section{APPENDIX 5}

Wind statistics

The potential influence of wind on internal transient flows (Fig. 4) raises the question of how likely such winds would be in the environment these mounds inhabit. As part of a study on termite ventilation carried out in 2000, wind speeds around $\sim 400$ mounds of $M$. michaelseni were measured at $30 \mathrm{~s}$ intervals over periods of $30 \mathrm{~min}$. Wind speeds were measured at heights of $0.5,1.5$ and $2.5 \mathrm{~m}$ using cup anemometers mounted on a mast, for a total of $\sim 25,000$ 

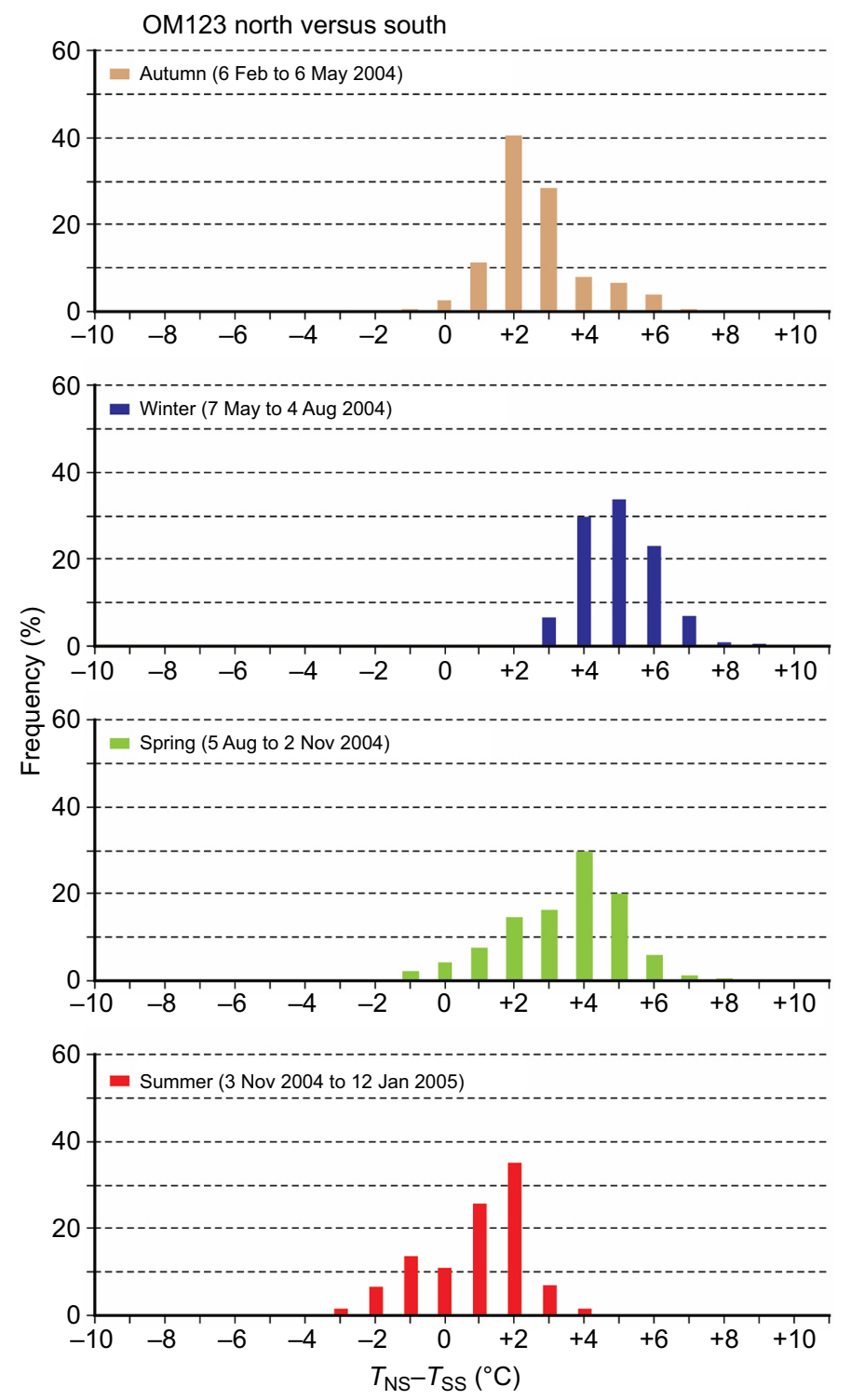

Fig. A5. Distribution of temperature differences between northern and southern side of a mound over the course of one year.

measurements of wind speed. The site was located approximately $100 \mathrm{~km}$ northwest from the site of the present study, in the same habitat type, semi-arid savanna. Distributions of wind speed at the three heights (Fig. A4) showed a skewed distribution of wind speeds at each height, with the upper tails extending to faster wind speeds at greater heights. We calculated the likelihood that a mound would be exposed to wind speeds of $3 \mathrm{~m} \mathrm{~s}^{-1}$ or higher. From inspection of Fig. 4, the wind speed of $3 \mathrm{~m} \mathrm{~s}^{-1}$ appears to be a threshold for a wind effect on internal transients. At a height of $0.5 \mathrm{~m}$, the likelihood was essentially nil that wind speed would exceed $3 \mathrm{~m} \mathrm{~s}^{-1}$. At a height of $1.5 \mathrm{~m}$, the likelihood that a mound would encounter a wind speed greater than $3 \mathrm{~m} \mathrm{~s}^{-1}$ was roughly $8 \%$. At a height of $2.5 \mathrm{~m}$, the likelihood that a mound would encounter a wind speed greater than $3 \mathrm{~m} \mathrm{~s}^{-1}$ was roughly $15 \%$. While sun-driven natural convection dominates internal flows of air at the most commonly encountered wind speeds in this habitat, the likelihood remains that wind-driven disturbance of internal flows during gusty conditions can stir air within the mound.

\section{APPENDIX 6}

Seasonal variation in the distribution of mound temperature

Solar-driven natural convection within the mound air space results in temperature differences within the mound of sufficient magnitude to drive air flows. The sun warms the north-facing surfaces of the mound differently from the south-facing surfaces, and this affects the temperature difference within the mound, in turn driving natural convection within the mound air spaces. This will change with the time of year because the position of the sun in the sky varies with the season. Although the zenith of the sun is usually in the northern sky, it can shift to the southern sky during the summer. This is likely to affect the differential solar heating of the mound upon which natural convection will depend. In 2004, detailed measurements of temperature within the mound and surrounding soils were carried out using Thermochron iButtons programmed to log temperatures every $6 \mathrm{~h}$. The site was located on the Omatjenne Agricultural Research Farm, roughly $70 \mathrm{~km}$ west of the site for the present study, in the same habitat type, arid savanna. For comparison with this study, distributions of the temperature difference between the northfacing superficial soil temperature $\left(T_{\mathrm{NS}}\right)$ and the south-facing superficial soil temperature $\left(T_{\mathrm{SS}}\right)$ for one mound (designated OM123) are presented in Fig. A5. Superficial soil temperature is measured at a depth of $10 \mathrm{~cm}$ from the mound surface, about $1.5 \mathrm{~m}$ above the surrounding soil. Distributions are plotted for the four austral seasons, with dates bracketing the solstices or equinoces. Thus, autumn data range from 6 February to 6 May, which brackets the autumnal equinox of 21 March.

Of the four austral seasons, the greatest differential heating occurs in winter, with the mound's north-facing surface most commonly being approximately $5^{\circ} \mathrm{C}$ warmer than its south-facing surface. Winter in Namibia is dry and cold, with termite activity confined mostly to the nest and underground. In the austral summer, differential heating is skewed toward warmer north-facing surface temperatures, but with significant differential heating of the south superficial face over the north superficial face. In the austral autumn and spring, the north superficial surface is consistently warmer than the south superficial surface, but not to the same extent as in the winter. During the austral winter, the modal temperature difference is $+5^{\circ} \mathrm{C}$, in the austral autumn, the modal temperature difference is $+2^{\circ} \mathrm{C}$, and in the austral spring, the modal temperature difference is $+4^{\circ} \mathrm{C}$.

The present study was carried out at a time of year when differential heating of the mound by the sun is at its greatest extent, but also at a time of year when mound rebuilding is infrequent to non-existent (Turner et al., 2006). Both are likely to contribute to sun-driven natural convection dominating movements of mound air. Mound porosity, for example, depends upon active remodeling of the mound, which occurs in the austral summer, which is the wet season in Namibia. Thus, mound porosity at the time this study was carried out, when building activity is low, is likely to be small. The relative effects of wind- and solar-driven differential heating may therefore vary between seasons.

\section{Acknowledgements}

We thank B. Pinshow for useful discussions, B. Ocko for help with field experiments, J. MacArthur and A. Takei for advice on electronics, J. Weaver for help with 3D printing, and the Cheetah Conservation Fund for accommodation and providing access to their field sites.

\section{Competing interests}

The authors declare no competing or financial interests. 


\section{Author contributions}

Conceptualization: L.M., S.O., H.K., S.T.; Methodology: S.O., H.K., S.T., R.S.;

Software: S.O., H.K.; Validation: L.M., S.O., H.K.; Formal analysis: S.O., H.K., R.S.; Investigation: S.O., H.K., D.A., P.B.; Resources: L.M.; Writing - original draft: L.M., S.O., H.K.; Writing - review \& editing: L.M., S.O., H.K., S.T., R.S.; Visualization: S.O.; Supervision: L.M.; Funding acquisition: L.M., S.T.

\section{Funding}

The Human Frontier Science Program supported this study. S.O. was additionally supported by the Henry W. Kendall physics fellowship (MIT) and the Karel Urbanek physics fellowship (Stanford University).

\section{Supplementary information}

Supplementary information available online at

http://jeb.biologists.org/lookup/doi/10.1242/jeb.160895.supplemental

\section{References}

Dangerfield, J. M., Mccarthy, T. S. and Ellery, W. N. (1998). The mound-building termite Macrotermes michaelseni as an ecosystem engineer. J. Trop. Ecol. 14, 507-520.

Datta, S. S., Chiang, H., Ramakrishnan, T. S. and Weitz, D. A. (2013). Spatial fluctuations of fluid velocities in flow through a three-dimensional porous medium. Phys. Rev. Lett. 111, 064501.

King, H., Ocko, S. and Mahadevan, L. (2015). Termite mounds harness diurnal temperature oscillations for ventilation. Proc. Natl Acad. Sci. USA 112, 11589-11593.

Korb, J. (2003). Thermoregulation and ventilation of termite mounds. Naturwissenschaften $\mathbf{9 0 ,}$ 212-219.
Korb, J. and Linsenmair, K. E. (2000). Ventilation of termite mounds: new results require a new model. Behav. Ecol. 11, 486-494.

Lebon, L., Oger, L., Leblond, J., Hulin, J. P., Martys, N. S. and Schwartz, L. M. (1996). Pulsed gradient NMR measurements and numerical simulation of flow velocity distribution in sphere packings. Phys. Fluids (1994-present) 8, 293-301.

Loos, R. (1964). A sensitive anemometer and its use for the measurement of air currents in nests of Macrotermes natalensis. In Etudes sur les termites Africains (ed. A. Bouillon). Paris: Masson.

Luscher, M. (1961). Air-conditioned termite nests. Sci. Am. 205, 138-145.

Olson, D. E., Parker, K. H. and Snyder, B. (1984). A pulsed wire probe for the measurement of velocity and flow direction in slowly moving air. J. Biomech. Eng. 106, 72-78.

Ruelle, J. (1964). L'architecture du nid de macrotermes natalensis et son sens fonctionnel. In Etudes sur les termites Africains (ed. A. Bouillon), pp. 327-362. Paris: Masson.

Turner, J. S. (1994). Ventilation and thermal constancy of a colony of a southern African termite (Odontotermes transvaalensis: Macrotermitinae). J. Arid Environ. 28, 231-248.

Turner, J. S. (2000). Architecture and morphogenesis in the mound of Macrotermes michaelseni (Sjöstedt) (Isoptera: Termitidae, Macrotermitinae) in northern Namibia. Cimbebasia 16, 143-175.

Turner, J. S. (2001). On the mound of Macrotermes michaelseni as an organ of respiratory gas exchange. Physiol. Biochem. Zool. 74, 798-822.

Turner, J. S. and Soar, R. C. (2008). Beyond biomimicry: What termites can tell us about realizing the living building. In 1st International Conference on Industrialised, Integrated, Intelligent Construction (I3CON), p. 221.

Turner, J., Marais, E., Vinte, M., Mudengi, A. and Park, W. (2006). Termites, water and soils. Agricola 16, 40-45. 